\title{
STRETCHING AS A PART OF A STRATEGY FOR THE PREVENTION AND MANAGEMENT OF CHRONIC LOW BACK PAIN
}

\author{
P. Angelova* \\ Medical College, Trakia University, Stara Zagora Bulgaria
}

\begin{abstract}
Tasks in the treatment of chronic pain in the lumbar region include a decrease in the degree of pain and improvement of daily activity, prevention of musculoskeletal disorders, as well as maintenance of working capacity. The aim of this study is to investigate the application of stretching exercises as a way to restore muscle balance and to prevent recurrent pain in the back. Tasks: To study available publications on the application of stretching exercises in lumbar pain; To draw conclusions after analyzing the data. Results: The proposed special exercises for fitness, muscle balance and normal tone of the dorsal muscles are important for the restoration and protection of patients from back pain. Conclusion: the regular conduct of kinesitherapy for prophylaxis, outside the acute period, would play a role in keeping the spine in condition. This would significantly limit the incidence of relapses, clinical practice in our country still lags behind this approach, unfortunately.
\end{abstract}

Key words: exercise therapy, rehabilitation program, muscle balance.

\section{INTRODUCTION}

Pain in the lower back is a common cause of a decrease in physical activity and creates a vicious cycle that is difficult to change. Restoring muscle balance and improving the mobility of the spine are the most important tasks of kinesiotherapy in pain in the lumbosacral region. This necessitates the need to search for serious and analytical ways of treatment, reduce relapse and prevention. The specialists in rehabilitation medicine and kinesitherapists play a key role in creating an adequate treatment algorithm, whose practical application would provide and better quality of life for patients. The most effective types of exercises for chronic or acute back pain are still controversial, but Lizier et al. (1) indicate that exercise therapy is probably the most widely used conservative treatment around the world. Physical exercise according to van Middelkoop (2); Kostadinov (3); Lizier et al. (1) have a tested effect for controlling pain in the lower back. In a systematic review of

\footnotetext{
*Correspondence to: Petya Angelova, Trakia University Medical College, Bulgaria, Stara Zagora 6003, Georgi Apostolov str. 14, E_mail: pe_angelova@abv.bg phone number: $+359886441285$
}

randomized controlled trials, Krismer M, van Tulder (4) found that specific exercises are effective in chronic back pain and accelerate return to normal daily activities and work. Mihajlova et al. (5) indicate that the systematic performance of special exercises for the dorsal muscles helps to create a good body posture and a good base for maintaining the pelvis in the correct position.

The aim of this study is to investigate the application of stretching exercises as a way to restore muscle balance and to prevent recurrent pain in the back.

Tasks:

- To explore the available publications on the application of stretching exercises in lumbar pain

- Draw conclusions after analyzing the data

Stretching exercises as part of the rehabilitation process in lumbar pain

The stretching is a therapeutic method, included in medical rehabilitation. It is used to increase muscle length and joint volume, also to strengthen collagen fibers. The American College of Sports Medicine also recommends static stretching as part of a general fitness program. Some scientific publications on the 
effectiveness of the stretching are looking at the immediate results and other results over a period of time include the different muscles or muscle groups, covering different populations and groups. This necessitates the need to search for and create individualized stretching programs, maximally effective as an approach and performance. In order to draw conclusions and recommendations based on scientific research, these factors should be taken into account. The difficulty of determining the effectiveness of the stretching comes from the fact that the rehabilitation events are supplemented by other means of impact on the muscles. Available publications on static stretching methods prove effective in terms of improved flexibility and elongation of muscles, but with some differences in different groups of people.

Moore et al. (6); Curry et al. (7); Dalrymple et al. (8) describe the peculiarities of the results obtained when applying stretching to specific populations of humans. According to Hakkinen et al. (9); Ylinen et al. (10), the 12-month application of stretching is just as effective as muscle enhancement exercises or manual therapy in chronic pain patients.

In patients with chronic musculoskeletal pain after three weeks of static stretching there is an increased tolerance to stretching the muscles. Matzuridis et al. (11) trace the effectiveness of stretching for dorsal muscles, filled for 15-20 minutes a day, three times a week, for 6 months. Based on the results after applying the stretching program, Lawand et al. (12) report on effective reduction of pain, improvement of functional condition, certain aspects of quality of life (emotional, limitations in physical functioning, vitality and mental health) in patients with chronic lumbar pain.

Gawda P et al. (13) also reports that selected techniques for stretching therapy improve the range of movement of the spine and reduce pain in patients with chronic nonspecific lumbar pain. Studies of Khalil et al. (14) in patients with chronic lumbar pain indicate that patients undergoing systemic stretching for 2 weeks lead to a significant improvement in functional abilities and a decrease in the level of pain. Angelova (15) Published data on the reduction of myofascial pains by static stretching, with duration of holding in the stretched position from 10 to $20 \mathrm{sec}$. and 3 to 5 repetitions. When a stretching program was included in the treatment of muscular traumas of the muscles Ishiocruralis, Malliaropulos et al. (16), found that the time to restore normal range of movement was significantly shorter compared to treatment without stretching exercises. This method, according to Jonson (17) can be performed before or after other exercises, and recommended by therapists as part of a rehabilitation program performed at home or in a medical institution. Through purposeful stretching according to Popov et al. (18). A correction of the muscles with hypertonus and or shortening, normal range of movement and mobility is achieved. They specify that the results should be maintained and then with regular exercises to make correction of aggravating orthostatic and biomechanical factors. Muscle relaxation and stretching exercises according to Fleckenstein et al. (19), Dyakova and Angelova (20) are useful for reducing pain, allowing patients to participate in an active exercise program.

Stretching exercises for the prevention of back pain.

Prevention of recurrent back pain is an important part of a rehabilitation programs to avoid complications, worsening and lesions of the structures of the spine. Modern studies show that the good condition of the lumbar spine depends on many factors and one of them is the elasticity of the ishiocruralis muscles Popov et al. (18). The shortened position of the flexors causes increased lumbar lordosis and further to the development of pain syndrome in the lumbar region. Potted paravertebral muscles also lead to a limited normal mobility. Reduced full range of movement in the segments of the spine is a prerequisite for narrowed intervertebral spaces and thus gives the possibility of trauma under load. At the Kosuke et al. (21) the experiment was found to reduce the hardness and tightening of the ishiocrurali muscles after 3 minutes of performance static stretching. Feland et al. (22) found that a 60 -second holding in static stretching of the ishiocruralis muscles led to greater improvements in flexibility in older people than those recommended by other authors 15 to 30 seconds. Rider et al. (23) published results from the application of static stretching of the muscles for ten weeks, showing increased mobility of the spine (flexion and extension) in older people. Some writers have been targeting the development of training programs for back pain. These programs explain the biomechanical features of the spine, give practical guidance on how to maintain body posture, offer special exercises for 
conditioning, muscle balance and a normal tone of the dorsal muscles. This is important for restoring and protecting patients from back pain. The regular conduct of kinesitherapy for prophylaxis, outside the acute period, would play a role in keeping the spine in condition. This would significantly limit the incidence of relapses. A good prophylactic measure is the dissemination of information brochures on the principles of labor hygiene and rest in conditions associated with back pain. Clinical practice in our country is still lagging behind this approach, unfortunately.

Recommendations:

More research is also needed on the topic of the effects of therapeutic stretching in chronic back pain, and the length of the follow-up will vary over a longer period.

The choice of adequate treatment also depends on the availability of high-quality published research and normative data.

Kinesitherapy for patients with musculararticular pain to focus on the correction of muscles with hypertonius and or shortening by purposeful stretching, as well as correction of aggravating orthostatic and biomechanical factors.

\section{CONCLUSIONS}

From a practical point of view, stretching exercises are an affordable and easily workable method with a good therapeutic effect in pain in the musculoskeletal system of a functional nature. Muscle spasm and muscle imbalance are positively influenced by the administration of stretching exercises.

The problems related to the prevention and treatment of people with back pain necessitate a complex and specialized approach.

The studied publications give reason therapeutic stretching to be recommended in pain management programs.

The modalities of implementation and results remain controversial due to some discrepancies in terms of duration and frequency of stretching of this method of therapy. It is good to gather more evidence to allow conclusions to be drawn about the effectiveness of programs involving stretching exercises.

\section{REFERENCES}

1. Lizier, D., Perez, M., Sakata, R., Exercises for Treatment of Nonspecific Low Back Pain Rev Bras Anestesiol 2012; 62: 6: 838-
846 DOI: 10.1016/S0034-7094(12)70183-

6.

2. vanMiddelkoop, M., Rubinstein, S., Verhagen, A. et al., Exercise therapy for chronic nonspecific low-back pain. Best Pract Res ClinRheumatol., 2010; 24:193.

3. Kostadinov, D., Lumbar-sacral syndrome, MF Sofia, Sofia, 1983.

4. Krismer, M., van Tulder, M. - Strategies for prevention and management of musculoskeletal conditions. Low back pain (non-specific). Best Pract Res Clin Rheumatol, 2007;21:77-91. 1.

5. Mihajlova, M., Filkova, S., Michaleva, V., Some Aspects of the Conservative Treatment and Prevention of Lumbar Disc Disease Scripta Scientica Salutis Publicae, vol. 2, 2016, suppl. 1, pp. 95-100 Medical University of Varna.

6. Moore, M., Hutton, R., Electromyographic investigation of muscle stretching techniques. Med Sci Sports Exerc. 1980;12(5):322-329 [PubMed].

7. Curry, B., Chengkalath, D., Crouch G., Romance, M., Manns P., Acute effects of dynamic stretching, static stretching, and light aerobic activity on muscular performance in women. J Strength Cond Res. Sep 2009;23(6):1811-1819 [PubMed].

8. Dalrymple, K., Davis, S., Dwyer, G., Moir, G., Effect of static and dynamic stretching on vertical jump performance in collegiate women volleyball players. Strength J. Cond Res. Jan 2010;24(1):149-155 [PubMed].

9. Hakkinen, A., Kautiainen, H., Hannonen, P., Ylinen J., Strength training and stretching versus stretching only in the treatment of patients with chronic neck pain: a randomized one-year follow-up study. Clin Rehabil. Jul 2008;22(7):592600 [PubMed].

10. Ylinen, J., Kankainen, T., Kautiainen, H., Rezasoltani, A., Kuukkanen, T., Hakkinen, A., Effect of stretching on hamstring muscle compliance. J Rehabil Med. Jan 2009;41(1):80-84 [PubMed].

11.Matzuridis, A., Kraydjikova, L., Andonova T., An.G. Matzuridis Self-stretching exercises for prevention of back pain by patients with osteoporosis Proceedings of the II All-Russian Scientific-Practical Conference with International Participation "Medical Physical Culture: Achievements and Prospects for Development" (May 2728, 2013) // Under the general editorship of Ivanova, NL, Kozyreva, OV - M .: FGBOU VPO "RGUFKSMiT", 2013. - $270 \mathrm{p} . \therefore$ ill. UDC 796.01: 061.3 C 23. 
12.Lawand, P., Lombardi, I. Jr., Jones, A., Sardim, C., Ribeiro, L., Natour, J., Effect of a muscle stretching program using the global postural reeducation method for patients with chronic low back pain: A randomized controlled trial Joint Bone Spine, Volume 82, Issue 4, July 2015, Pages 272-277 https://doi.org/10.1016/j.jbspin.2015.01.015 13.Gawda, P., Dmoszyńska-Graniczka, M., Pawlak, H., Cybulski, M., Kiełbus, M., Majcher, P., Buczaj, A., Buczaj, M., Evaluation of influence of stretching therapy and ergonomic factors on postural control in patients with chronic non-specific low back pain Annals of Agricultural and Environmental Medicine 2015, Vol 22, No $1,142-146$.

14.Khalil, T., Asfour, S., Martinez, L., Waly, S., Rosomoff, R., Rosomoff, H., Stretching in the rehabilitation of low-back pain patients. Spine (Phila Pa 1976). 1992 Mar;17(3):311-7 [PubMed].

15.Angelova, P., Therapeutic Stretching in Myofascial Pain, Third International Conference on Kinesiology, October 27-28, 2011, "St. St. Cyril and Methodius, ISSN 1313-244X, p. 260, 2011.

16.Malliaropoulos, N., Papalexandris, S., Papalada, A., Papacostas, E., The role of stretching in rehabilitation of hamstring injuries: 80 athletes follow-up. Med Sci Sports Exerc. May 2004;36(5):756-759 [PubMed].

17.Jonson, J., Therapeutic stretching. Handson Guides for Therapists, ISBN: 978-14504-1275-9, 2012, стр. 43.

18. Popov, N., Dimitrova, E., TashevaGancheva, R., Ganchev, D., Popova-
Lubenova, D., Sazdova, L., Lyubenova, D., Markovska, G., Kinesitherapy in sports practice General Methodology, ISBN-10-954718-194-7, NSA-Press, S., 2006

19. Fleckenstein, J., Zaps, D., Ruger, L. et al. Discrepancy between prevalence and perceived effectiveness of treatment methods in myofascial pain syndrome: results of a cross-sectional, nationwide survey. BMC Musculoskelet Disord. Feb 11 2010; 11:32.

20. Dyakova, G., Angelova, P., Kinesitherapy aids, Ak. Ed. TRU, Stara Zagora, p.186, ISBN 978-954338-045-9, 2012.

21. Fujita, K., Nakamura, M., Umegaki, H., Kobayashi, T., Nishishita, S., Tanaka, H., Ibuki, S., Ichihashi, N., Journal of Sport Rehabilitation, 2018, 27:1, 66-72, Effects of a Thermal Agent and Physical Activity on Muscle Tendon Stiffness, as Well as the Effects Combined With Static Stretching.

22. Feland, J., Marin, H., Effect of submaximal contraction intensity in contract-relax proprioceptive neuromuscular facilitation stretching., $\mathrm{Br} \quad J \quad$ Sports Med., Aug 2004;38(4):E18. [PMC free article] [PubMed].

23. Rider, R., Daly J., Effects of flexibility training on enhancing spinal mobility in older women., $J$ Sports Med Phys Fitness., Jun 1991;31(2):213-217 [PubMed]. 